\title{
NOTES
}

\section{Polyamide-Smectic Oligomer Graft Copolymers as Compatibilizers for Polymer Alloys}

\author{
Kazuo SugiYama* and Syotaro SHIRAISHI \\ Department of Industrial Chemistry, Faculty of Engineering, Kinki University, \\ Takaya, Higashihiroshima, Hiroshima 739-21, Japan
}

(Received March 8, 1995)

\begin{abstract}
KEY WORDS Phosphorylation Polycondensation / Aromatic Polyamides / Smectic Macromonomer / Graft Copolymer / Thermal Properties / Mechanical Properties /
\end{abstract}

Interest has been devoted to preparing graft and block copolymers for stabilizing the interphase of polymer blends because different polymers are generally non-compatible. Some graft and block copolymers containing the liquid crystalline segments have been synthesized so far. ${ }^{1-7}$ In the previous paper, ${ }^{8}$ the authors reported on the smectic oligomer graft copolyamide, PA-3B, obtained using a macromonomer technique (Figure 1). The introduction of smectic oligomer (MacMHB) with a definite molecular weight $\left(M_{n}=4200\right)$ into a parent polyamide PA-2 results in improved solubility in common organic solvents. The present paper describes a series of graft copolyamides (PA-3A-D) having MacMHB of different molecular weights $\left(M_{n}=2300\right.$ $4600)$ to obtain basic information on compatibilizers for polymer blends of $m$-aramid and succinic acid polyester containing the biphenyl moiety, SAPE.

\section{EXPERIMENTAL}

Synthesis of Macromonomer, MacMHB-A-D

A series of MacMHB with different molecular weights was synthesized by radical polymerization of 4-(6-methacryloyloxyhexyl- oxy)-4'-methoxybiphenyl [MHB: $\mathrm{K}$ 63.1 $\mathrm{S}_{\mathrm{A}}$ 76.2 I] initiated with 2,2'-azobisisobutyronitrile (AIBN) in the presence of thiomalic acid (TMA) in tetrahydrofuran at $60^{\circ} \mathrm{C}$, by changing the molar ratio of MHB:TMA: AIBN. MacMHB was purified by reprecipitation from a tetrahydrofuran-petroleum ether solvent system and characterized by the method in the previous paper. ${ }^{8}$

\section{Synthesis of Graft Copolyamides, PA-3A-D}

PA-3A-D was synthesized by phosphorylation polyamidation of 4-aminodiphenyl ether (ADPE) and MacMHB in the presence of 4-aminobenzoic acid (ABA) with the molar ratio of $1: 1: 5$ for ADPE: MacMHB:ABA according to the procedure described previously. ${ }^{8}$

Synthesis of Liquid Crystalline Succinic Acid Polyester, SAPE

4,4'-Bis(6-hydroxyhexyloxy)biphenol $\quad[\mathrm{K}$ 97.5 S 175.7 I] was polycondensated with succinic acid in the presence of a catalytic amount of $p$-toluenesulfonic acid in 1,2-dichloroethane using a Soxhlet extractor. Liquid crystalline succinic acid polyester, SAPE, shows phase transition temperature of K $123.3 \mathrm{~S} 131.0 \mathrm{I}$

\footnotetext{
* To whom correspondence should be addressed.
} 


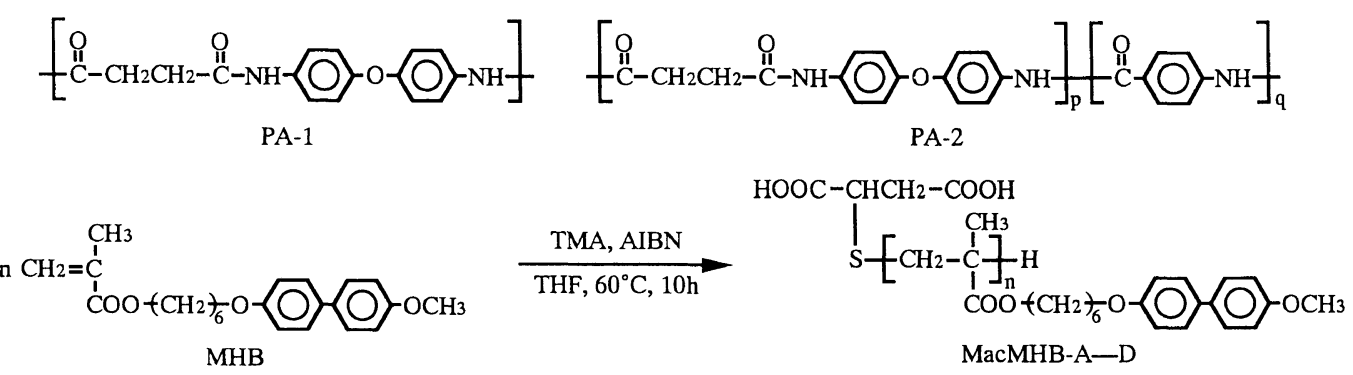

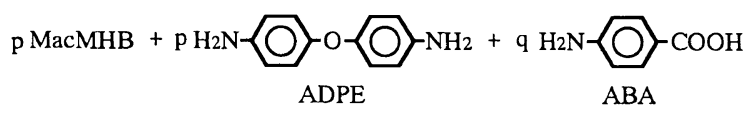
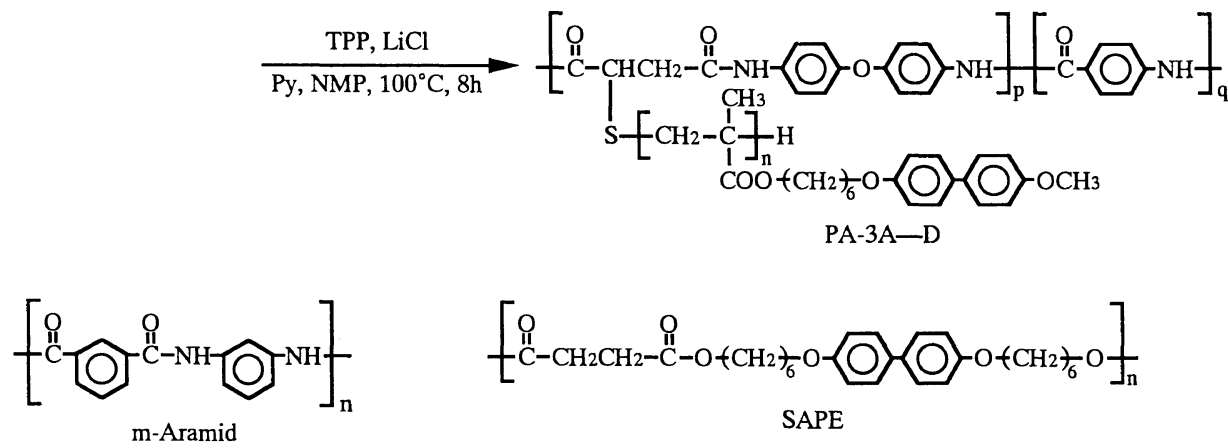

Figure 1. Structures of various polymers.

and has an intrinsic viscosity $[\eta]=0.50 \mathrm{dl} \mathrm{g}^{-1}$ (1.0 $\mathrm{g} \mathrm{dl}^{-1}$ in $N$-methyl-2-pyrrolidone). ${ }^{9}$

\section{Preparation of Films}

$20 \mathrm{ml}$ of $\mathrm{N}$-methyl-2-pyrrolidone solution containing a known amount of $m$-aramid (supplied by Tsukuba Research Laboratory, Nippon Oil \& Fat Co., Ltd.), SAPE, and PA-3 were cast on a mercury bath with $6.0 \mathrm{~cm}$ diameter. The solvent was evaporated by irradiation with an infrared lamp and ternary blends (alloy II) of films were obtained. Binary blends (alloy I) of $m$-aramid and SAPE were also prepared. The films were completely dried in vacuo at $80^{\circ} \mathrm{C}$ for $5 \mathrm{~h}$. The films were annealed at $130^{\circ} \mathrm{C}$ at $100 \mathrm{kgf} \mathrm{cm}^{-2}$ pressure for $1 \mathrm{~h}$ with a Tester test press apparatus, followed by cutting into rectangular strips $2 \mathrm{~mm}$ wide, $20 \mathrm{~mm}$ long and $0.06-0.08 \mathrm{~mm}$ thick.

\section{Measurements}

Tensile testing was performed with a Seiko
TMA/SS 120c using a thin polymer blend film of rectangular strip. The elongation rate was kept at $0.1 \mathrm{~mm} \mathrm{~min}^{-1}$ at ambient temperature.

\section{RESULTS AND DISCUSSION}

Preparation and Characterization of MacMHB$A-D$

Four kinds of dicarboxyl-terminated macromonomers (MacMHB-A-D) with different molecular weights from $M_{n}=4600$ to $M_{n}=$ 2300 were prepared by the radical polymerization of MHB initiated with AIBN in the presence of TMA as a chain transfer agent in tetrahydrofuran at $60^{\circ} \mathrm{C}$, by changing the ratio of MHB: TMA : AIBN from $1: 0.10: 0.01$ to $1: 0.60: 0.01$. MacMHB-A-D exhibited a monotropic liquid crystalline mesophase with a focal conic texture. The isotropization temperature $\left(T_{\mathrm{i}}\right)$ of MacMHB-A-D decreased gradually from $123^{\circ} \mathrm{C}$ to $114^{\circ} \mathrm{C}$ with 
Table I. Preparation and characterization of MacMHB with various molecular weights

\begin{tabular}{|c|c|c|c|c|c|c|c|c|c|c|}
\hline \multirow{3}{*}{ МасMHB } & \multirow{3}{*}{$\mathrm{MBH}$} & \multirow{3}{*}{ TMA } & \multirow{3}{*}{ : AIBN } & \multicolumn{3}{|c|}{ Mol. wt. } & \multicolumn{2}{|c|}{ Phase transition temperature ${ }^{a}$} & \multirow{3}{*}{$\frac{2 \theta}{\text { degree }}$} & \multirow{3}{*}{$\begin{array}{l}d \\
\AA\end{array}$} \\
\hline & & & & \multirow{2}{*}{$\begin{array}{c}\text { Titration, } \\
M_{n}\end{array}$} & \multicolumn{2}{|c|}{ GPC } & \multirow{2}{*}{$\frac{T_{\mathrm{m}}}{{ }^{\circ} \mathrm{C}}$} & \multirow{2}{*}{$\frac{T_{\mathrm{i}}}{{ }^{\circ} \mathrm{C}}$} & & \\
\hline & & & & & $M_{n}$ & $M_{w} / M_{n}$ & & & & \\
\hline A & 1 & $: 0.10$ & $: 0.01$ & 4900 & 4600 & 1.41 & 115 & 123 & 3.44 & 25.7 \\
\hline $\mathbf{B}^{\mathrm{b}}$ & 1 & $: 0.15$ & $: 0.01$ & 4350 & 4200 & 1.33 & 112 & 119 & 3.42 & 25.8 \\
\hline $\mathrm{C}$ & 1 & $: 0.30$ & $: 0.01$ & 3000 & 2900 & 1.24 & 113 & 117 & 3.42 & 25.8 \\
\hline $\mathrm{D}$ & 1 & $: \quad 0.60$ & $: \quad 0.01$ & 2300 & 2300 & 1.17 & 105 & 114 & 3.37 & 26.2 \\
\hline
\end{tabular}

${ }^{a} T_{\mathrm{m}}$ and $T_{\mathrm{i}}$ represent temperatures of melting process, and isotropic melt, respectively. ${ }^{\mathrm{b}}$ Data in ref 8 .

decreasing $M_{n}$. MacMHB-A-D showed a small angle $\mathrm{X}$-ray diffraction (SAX) peak at around $2 \theta=3.4^{\circ}$ corresponding to an interplanar spacing of $d=26 \AA$, which was assigned to the layer spacing in a smectic mesophase. Characteristics of a series of MacMHB-A-D are summarized in Table $\mathrm{I}$, along with data for MacMHB-B from previous paper. ${ }^{8}$

\section{Preparation and Characterization of Graft Copolyamides, $P A-3 A-D$}

Phosphorylation polyamidation ${ }^{10-12}$ was conducted for the synthesis of PA-3A-D with the molar ratio of $1: 1: 5$ for ADPE: MacMHB-A-D:ABA in feed. The results of polycondensation are summarized in Table II, along with data for PA-3B described previously. ${ }^{8}$ IR spectra of PA-3A-D showed specific absorptions of $\mathrm{N}-\mathrm{H}$ stretch in $3330-3350 \mathrm{~cm}^{-1}$ and $\mathrm{C}=\mathrm{O}$ stretch of amide linkage in $1650-1660 \mathrm{~cm}^{-1}$ as well as $\mathrm{C}=\mathrm{O}$ stretch of ester in $1720-1730 \mathrm{~cm}^{-1}$. PA$3 \mathrm{~A}-\mathrm{D}$ is thus the sum of absorption of the polyamide segment and grafting MacMHB parts. From GPC measurement, the chromatogram of PA-3B, for instance, indicated a unimodal peak of $M_{n}=6000$, which did not show the starting MacMHB-B $\left(M_{n}=4200\right)$ as described previously. ${ }^{8}$ It was also found that PA-3A was thermally degraded through a two step mechanism whereas PA-3A decomposed randomly as mentioned below. These results demonstrate the formation of graft copoly- mer made up of polyamide backbone and grafting MacMHB parts.

From elemental analysis, the molar ratio of poly ( $p$-benzamide)(PBA) segment in PA-3 increased from $q=0.91$ to $q=0.98$. with decreasing $M_{n}$ of the starting MacMHB. The $[\eta]$ of PA-3 increased with the content of PBA segment.

The degree of crystallinity $(X)$ decreased with increasing content of PBA segment, because a rod-like character of PBA segment prevented the MacMHB molecules in PA-3 from smectic orienting.

PA-3A and PA-3B showed a SAX peak at $2 \theta=3.43^{\circ}$ corresponding to an interplanar spacing of $d=25.7 \AA$. This indicates that the smectic phase of the grafted MacMHB remains even in PA-3A and PA-3B.

PA-3A and PA-3B with $q \leqq 0.94$ were soluble in various solvents such as $N$-methyl-2-pyrrolidone, hexamethylphosphoramide, methyl sulfoxide, and even in tetrahydrofuran, while neither solubility nor swelling was observed in common organic solvents other than sulfuric acid for PA-3C and PA-3D with $q \geqq$ 0.97 .

\section{Thermal Properties}

PA-3A as well as PA-3B ${ }^{8}$ showed a mesophase, whereas no other graft copolyamides exhibited a melting process. It the case of PA-3A, the melting process indicated by two endothermic peaks at $120^{\circ} \mathrm{C}$ (melting point) 


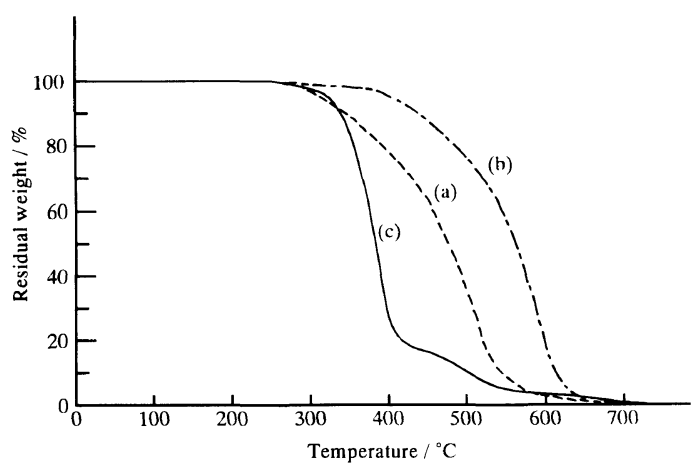

Figure 2. TG curves of PA-1 (a), PA-2 (b), and PA-3A (c).

and $128^{\circ} \mathrm{C}\left(T_{\mathrm{i}}\right)$ is followed by decomposition beginning at $339^{\circ} \mathrm{C}$. It is considered that PA-3A and PA-3B form the microphase-separated biphasic structure. The thermal stability of PA-3A as a typical instance was studied by TG-DTA measurements in air as shown in Figure 2, together with that of PA-1 and PA-2. PA-1 and PA-2 seem to decompose through random fission of the polyamide backbone, whereas PA-3A degrades via a two-step mechanism including the decomposition of the grafting MacMHB parts and polyamide backbone. The thermal properties of PA-3 are summarized in Table II.

\section{Compatibilizing Ability}

Prior to testing the compatibilizing ability of PA-3, the mechanical properties of the binary blends (alloy I) of $m$-aramid and SAPE were examined. Tensile strength $(\sigma)$, tensile modulus $(E)$, and ultimate elongation $(\varepsilon)$ versus weight ratio of two components for alloy I are shown in Figures 3, 4, and 5 (dotted line), respectively. Tensile strength and ultimate elongation of $m$-aramid fall by blending with SAPE, while the tensile modulus of alloy I with the weight ratio of $m$-aramid $: \mathrm{SAPE}=80: 20$ raises slightly more than that of $m$-aramid itself. Hence, ternary blends (alloy II) were prepared by adding $10 \mathrm{wt} \%$ of PA-3A-D as compatibilizer to alloy $\mathrm{I}$ with the weight ratio of $m$-aramid : SAPE $=80: 20$. The stress-strain

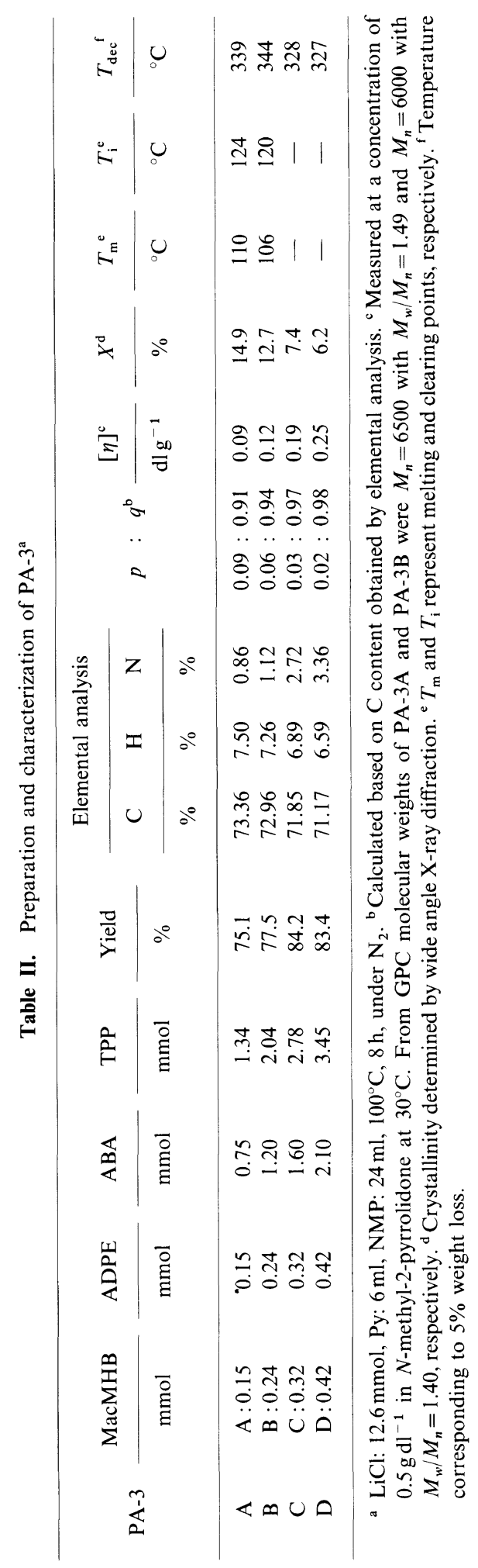

Polym. J., Vol. 27, No. 9, 1995 


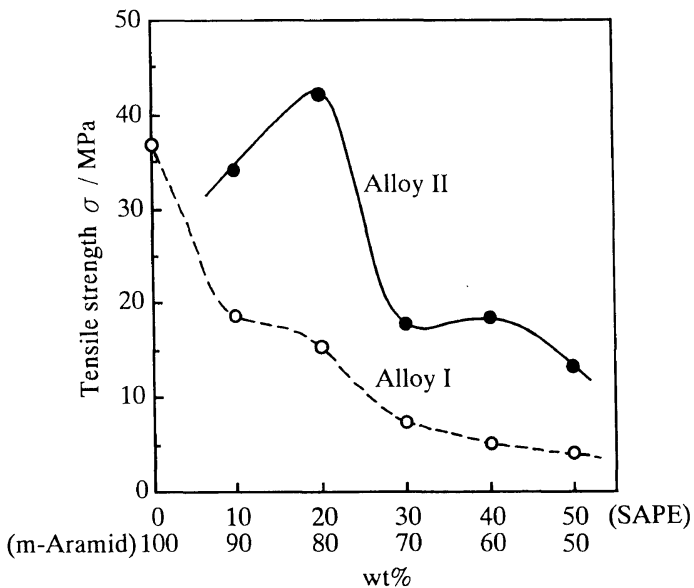

Figure 3. Tensile strength $\sigma$ vs. SAPE content in alloy I (dotted line, SAPE $/ m$-aramid) and alloy II (solid line, alloy I/PA-3B).

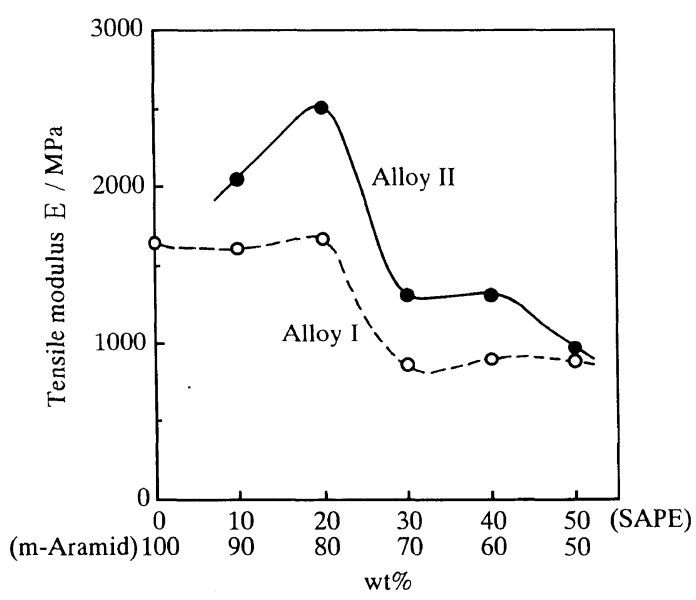

Figure 4. Tensile modulus $E$ vs. SAPE content in alloy I (dotted line, SAPE $/ m$-aramid) and alloy II (solid line, alloy I/PA-3B).

curves of a series of alloy II are shown in Figure 6. To see clearly the effects of $M_{n}$ of MacMHB in PA-3 on the mechanical properties of alloy II, tensile strength and ultimate elongation versus $M_{n}$ of MacMHB used for PA-3 are shown in Figure 7. PA-3B prepared from MacMHB with $M_{n}=4200$ yielded the highest tensile strength and largest ultimate elongation of alloy II. This means that when $m$-aramid and SAPE are compatibilized by adding PA-3 as the third component, an appropriate mole-

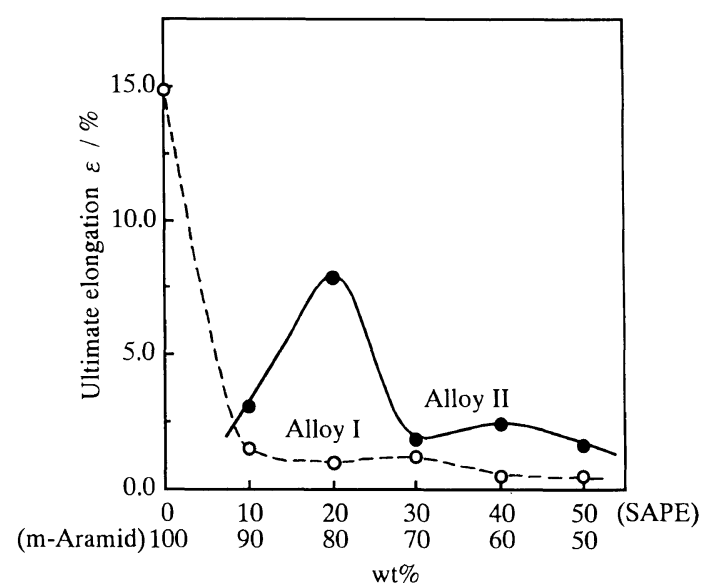

Figure 5 Ultimate elongation $\varepsilon v$ s. SAPE content in alloy I (dotted line, SAPE $/ m$-aramid) and alloy II (solid line, alloy I/PA-3B).

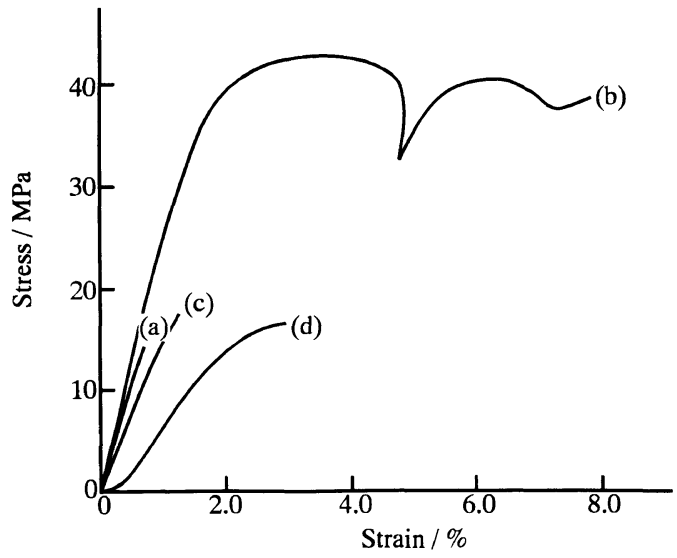

Figure 6. Stress-strain curves for a series of alloy II [alloy I ( $m$-aramid: $\mathrm{SAPE}=80: 20): \mathrm{PA}-3=90: 10$ ], alloy I/PA-3A (a), alloy I/PA-3B (b), alloy I/PA-3C (c), and alloy I/PA-3D (d).

cular weight of smectic MacMHB is needed because polyamide backbone and MacMHB part in PA-3 are expected to interact intermolecularly with $m$-aramid and SAPE, respectively. A series of alloy II was thus prepared by adding $10 \mathrm{wt} \%$ PA-3B to alloy I with different weight ratios of $m$-aramid and SAPE. Figures 3, 4, and 5 (solid line) show tensile strength, tensile modulus, and ultimate elongation versus the weight ratio of $m$-aramid and SAPE in alloy II. The mechanical properties 


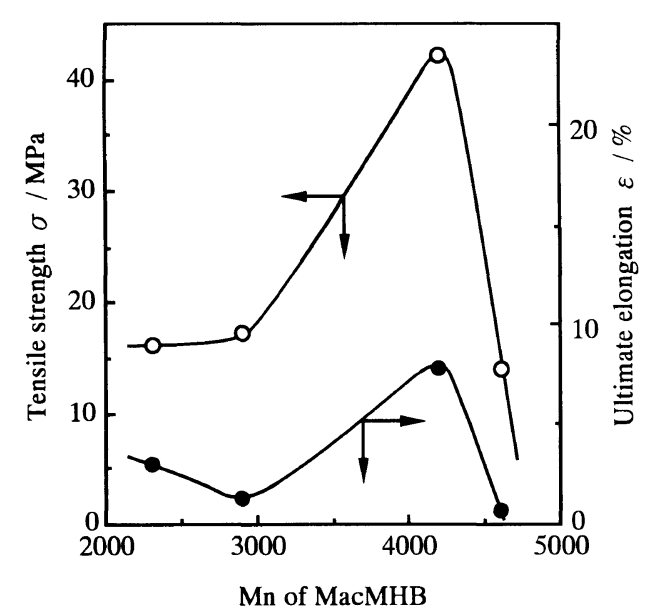

Figure 7. Effects of $M_{n}$ of MacMHB in PA-3 on tensile strength $\sigma$ and ultimate elongation $\varepsilon$ of alloy II [alloy I ( $m$-aramid : SAPE $=80: 20):$ PA-3A-D $=90: 10]$.

of alloy I were enhanced by the addition of PA-3 as a compatibilizer. It is noteworthy that tensile strength and tensile modulus of alloy II with the weight ratio of alloy I ( $m$-aramid: $\mathrm{SAPE}=80: 20): \mathrm{PA}-3 \mathrm{~B}=90: 10$ were higher than that of $m$-aramid.

The films of alloy I were turbid, whereas alloy II gave slightly transparent films. It is presumed that intermolecular hydrogen bonding interactions between $m$-aramid and poly- amide backbone of PA-3 as well as that between the mesogenic groups of SAPE and grafted MacMHB parts of PA-3 play important roles in the enhancement of the mechanical properties of alloy II.

\section{REFERENCES AND NOTES}

1. C. Pugh and V. Perec, Polym. Prepr. Am. Chem. Soc., Div. Polym. Chem., 27, 366 (1986).

2. Y. Chujo, H. Kobayashi, and Y. Yamashita, Polym. J., 20, 407 (1988).

3. A. Gottschalk and H.-W. Schmit, Liq. Cryst., 5, 1619 (1989).

4. M. Sato, T. Kobayashi, F. Komatsu, and N. Takeno, Makromol. Chem., Rapid Commun., 12, 269 (1991).

5. T. Heitz and O. W. Webster, Makromol. Chem., 192, 2463 (1991).

6. M. Hefft and J. Springer, Makromol. Chem., 193, 329 (1992).

7. K. Sugiyama, T. Oda, and Y. Yoshimitsu, Polym. J., 25, 769 (1993).

8. Y. Yoshimitsu, K. Sugiyama, S. Shiraishi, T. Oda, and T. Ohashi, Polym. J., 26, 551 (1994).

9. Preparation and characteristics of SAPE will be described in detail elsewhere.

10. F. Higashi, M. Goto, and H. Kakinoki, J. Polym. Sci., Polym. Chem. Ed., 18, 1711 (1980).

11. C.-P. Yang, J.-M. Cheng, and S.-H. Hinta, Makromol. Chem., 193, 445 (1992).

12. C.-P. Yang and W.-T. Chen, Makromol. Chem., 193, 2323 (1992). 